\title{
Exploring the Skills Set Development and its Job Market Relevance of the HND \\ Purchasing and Supply Programme.
}

\author{
Smile Dzisi ${ }^{1}$, ${ }^{*}$ Lomatey Isaac Toku ${ }^{1}$, Joshua Ofori-Amanfo ${ }^{2}$ \\ ${ }^{1}$ Koforidua Technical University, Koforidua, Ghana, Faculty of Business and Management Studies \\ 2 Pentecost University College, Accra, Ghana, Faculty of Business Administration \\ *anyemitoku@hotmail.com
}

\begin{abstract}
The study explores the skills set development and its job market relevance of the HND (Higher National Diploma) purchasing and supply programme in Ghana, using a grounded theory methodology. Semi-structured interviews, focus group discussions, observation and documentary analysis were used in the data collection, whereas thematic analysis was applied in the data analyses process. The research findings supported the widely held public perception that skills mismatch exist on the Ghanaian labour market. Besides, the HND Purchasing and Supply practitioners were found to lack managerial skills, confidence (psyche), analytical skills, critical thinking skills, specification development skills, computer skills in terms of data entry, word processing, excel and power point capabilities. Unfortunately, the study did not establish the existence of any practical on the job training in industry to resolve the identified skills deficiency. Although the research revealed that the Public Procurement Authority ( PPA) has been organizing some internships for HND Purchasing and Supply graduates, they still lack hands-on/ practical experience. Nonetheless, the study has confirmed the relevance to practice of the skills set imparted through HND Purchasing and Supply programme.
\end{abstract}

Keywords: skills set, skills mismatch, purchasing and supply, job market, unemployment.

\section{Introduction}

Skills set are important asset for individual workers and firms. However, the development of appropriate skills for the labour market has become a global issue. The Wold Economic Forum (WEF-2014) observes that policy-makers and social partners across the globe are increasingly becoming concerned with the mismatch between their workforce's skills and their labor markets' needs. The gap between the skills needed to perform a job and the actual skills possessed by individuals is referred to as 'skills mismatch' (WEF, 2014).

Higher Education (HE) plays a crucial role in the development of appropriate skill sets for the labour market. Recent years have seen increasing concerns being shared by employers in Ghana with regards to the skills set imparted by Ghana's HE system. The perception has been that the skills set imparted by some HE programmes do not match industry needs. The argument people often put up to support this claim is that many tertiary institutions develop academic programmes without any significant input from industry experts and with no recourse to trends on the labour market. The perception suggests the presence of skills mismatch on the Ghanaian labour market, a situation which potentially contributes to high rates of graduate unemployment. Skills mismatch raises the question of the extent to which graduates from Ghanaian Universities and Polytechnics will be able to contribute to the profitability of the firms they work for with consequences on the well being of the economy. WEF (2014) argues that poorly educated workforce, skills shortages and an under-skilled 
workforce tend to compromise economic development in developing and emerging economies.

The changing business environment is influencing a dramatic change in the way procurement is done. Handfield (2013) argues that a new face of procurement is emerging, which recognizes that a new set of value drivers must be developed in the face of massive environmental changes. The need to be efficient as well as the cost cutting approaches being pursued by firms has placed an urgent need on purchasing professionals to possess high level dynamic skills and higher educational institutions have the responsibility to promote this agenda.

Based on the literature prescription of the skill set requirement for the purchasing and supply profession (Tassabehji and Moorhouse, 2008; Giunipero et al., 2006) and how HE programmes are designed to deliver them, one might want to know if the HND Purchasing and Supply programme equip students with the required skill set and whether these skill set is what the Ghanaian industry needs. In this regard, this paper contributes to the supply management literature by exploring the market relevance of the skill set imparted by the Higher National Diploma (HND) in Purchasing and Supply programme and to determine the presence or otherwise of skills mismatch on the labour market for these graduates.

\subsection{Growing demand for purchasing skills}

The introduction of the HND in Purchasing and Supply programme in some Polytechnics in Ghana about some twenty years ago is an attestation of the increasing significance of purchasing skills in Ghana. Prior to the introduction of the HND programme, purchasing education was non-existent in the country's tertiary educational system. Persons interested in purchasing and supply management qualification had to pursue the United Kingdombased Chartered Institute of Purchasing and Supply programme. The increasing demand for the supply management skills has led to the introduction of degree programmes in logistics and supply chain management as part of the academic curriculum in some private and public universities too. These developments emphasizes the need for improved skills to meet market requirement.

The passage of the Public Procurement Law in 2003 by the government of Ghana for example recognises the importance of purchasing to the nation hence, the need for trained and qualified supply management professionals who will possess the requisite skills set to manage public sector procurement. The Polytechnics in Ghana produce majority of the practitioners in supply management found on the labour market. This paper represents an attempt to determine the job market relevance of the skills set imparted through the HND Purchasing and Supply programme.

\subsection{Skill set in organisational management}

Sauber et al., (2008) maintain that the need to educate professionals and equip them with new and higherlevel skills have become urgent. Skills, according to Peterson and Van Fleet (2004), is the ability either to perform some specific behavioural task or the ability to perform some specific cognitive process that is related to some particular task. Carla (1992) also describes skill as the learned capacity to carry out pre-determined results often with the minimum outlay of time, energy, or both. Skills thus denotes the ability to execute the tasks and duties of a job in a competent manner (Elias and McKnight, 2001).

Thurow (1994) emphasised that in the $21^{\text {st }}$ century, where organisations have virtually equal access to almost all resources, the skills to perform the job becomes a very important competitive factor. Thus it is the skills to effectively and efficiently execute job functions that make the difference between successful and failing organisations.

Skills needed for successful operation and management of an organization according to Carla (1992) includes; skills to learn; basic competence skills, computational skills; communication skills; problem-solving and creative thinking skills; selfesteem skills, motivation/goal skills; group effectiveness skills, interpersonal skills; organizational skills and leadership skills. It is widely believed that skills can positively influence not only humans but also firm's performances (Tassabehji and Moorhouse, 2008).

According to Giunipero and Pearcy (2000) there are seven types of skills. They outlined them as; Strategic Skills: that consists of: (1) strategic thinking, (2) supply base research, (3) structuring supplier relationships, (4) technology planning, and (5) supplier cost targeting; Process Management Skills: requires five key skills: (1) organization/ time management, (2) tactfulness, (3) written communications, (4) problem solving, and (5) conflict resolution; Team Skills: consists of teamwork, leadership, managing change, managing internal customers, and salesmanship; Decision 
making Skills: is of only two skills — ability to make decisions and computer literacy; Behavioral Skills: is composed of interpersonal communication, risk taking/entrepreneurial, creativity, and inquisitiveness; Negotiation Skills: The negotiation factor consists of four key skills: (1) negotiation, (2) customer focus, (3) influencing and persuasion, and (4) understanding business conditions and Quantitative Skills is composed of four skills: (1) computational, (2) technical, (3) blueprint reading, and (4) specification development. These type of skills highlight supply management as an important dimension of the operations of every organization which ought to be managed by people with the requisite skill set and experience.

\subsection{Changing landscape of procurement skills}

Cousins et al., (2006) state that skills requirement for purchasing professionals have changed considerably over the years perhaps due to the evolving nature of the profession. According to Cousins and Spekman (2003), a more sophisticated set of procurement skills and competences are required to effectively manage the buyer-supplier interface of the firm within the context of a global competitive environment. Cousins et al., (2006) further, contend that the role of purchasing has shifted from that of a buyer, focusing predominantly on price, delivery and quality, to that of managing strategic long-term, complex agreements between internal stakeholders and suppliers. Emphasis seems to be focused on overall total costs reduction, supplier coordination, supplier development, supplier market research, cost analysis, sourcing strategy formulation, benchmarking and outsourcing decision (Cousins et al., 2006; Carr and Smeltzer, 2000). Literature therefore suggest that procurement professionals now operate in a changing and dynamic environment and therefore makes it imperative for them to continuously update their existing skills in order to make any meaningful contribution to the financial, operational and strategic success of the firm (Tassabehji and Moorhouse, 2008; Giunipero and Pearcy, 2000; Giunipero et al., 2005).

Higher education, the knowledge base of industry, has a critical role to play in equipping purchasing professionals with these dynamic skills to meet the challenge. It has also been proven that enhanced purchasing skills affects organisational performance (Cousins et al., 2006; Carr and Smeltzer, 2000). Cousins et al., (2006) for instance found that high skill levels and knowledge in purchasing do impact significantly on the financial performance and operational efficiency in terms of quality improvement, design and reduction of lead times. Kolchin and Giunipero (1993) categorised skills requirement for purchasing into three areas namely, business skills, interpersonal skills and technical skills. Business skills include the ability to undertake market analysis, negotiation, manage relationships, global sourcing development, change management and planning and organisational skills. Interpersonal skills include risk taking, written and oral communication, conflict resolution, influence and persuasion, group dynamics, leadership, problem solving and international and cultural awareness. Examples of technical skills on the other hand include cost analysis, product knowledge, computer literacy, total quality management and government legislation (Humphreys et al., 2000). This view is shared by Giunipero et al., (2006) who add that as purchasing functions oscillate more towards the strategic approach in businesses, the key skill set required by these professionals include team building skills, strategic planning skills, communication skills, technical skills and broader financial skills.

The literature view that enhanced purchasing skills significantly influence firm performance (Cousins et al., 2006; Carr and Smeltzer, 2000), makes it imperative for purchasing and supply graduates to possess a skill set which will enhance their contribution towards corporate success. Carr and Smeltzer (2000) note that a number of universities have recognised the need to incorporate purchasing and supply management in their curriculum due to the growing recognition and demand for this type of business skills. The authors further add that these programmes have undergone considerable curriculum change over time in an effort to focus on the skill sets that most organisations desire when hiring candidates. The changing business environment therefore appears to propel the need for purchasing professionals to possess high level dynamic skills. Higher educational institutions represent the foundation for developing job market relevant skills and therefore have a greater responsibility in ensuring that such skills set are embedded in their degree and HND programmes.

\section{Methodology}

This study was exploratory in nature; hence the grounded theory approach was used. Thomas et al., (2011) state that grounded theory is discovery oriented, employing interpretative qualitative research 
methods to examine phenomenon that challenges people. Straus and Corbin (1998) assert that the grounded theory approach is very suitable for investigating challenging social processes. The research team is not aware of any existing research which has examined the skills mismatch for the HND Purchasing and Supply graduate. Since little is known about the phenomenon, Straus and Corbin (1998) maintain that qualitative methods are considered the appropriate research approach for initial discovery oriented inquiries.

Grounded theory is consistent with a researcher's interest in reasserting the primacy of intensive first-hand engagement with a social scene as the basis for theorizing (Locke, 2008). Observations are generated by using a naturalistic data collection strategies. These may include semi-structured interviews, participant observation and content analysis. Galunic and Eisenhardt (2001) applied the grounded theory methodology in a case study context to understand how dynamic capabilities reconfigure division resources in multi-business firms. Thus the present study's use of the grounded theory methodology in a case study context has precedence in the literature.

Based on the research process underpinning the grounded theory approach, we utilised qualitative methods in the data collection process. This approach enables the researchers to describe perceptions more accurately and thoroughly, interact with the staff in real day-to-day organizational contexts, have access to authentic and open answers from respondents because they are operating in their natural organizational settings. Semi-structured interviews, conversations, observations, focus group discussions and documentary analysis were used for the data collection exercise. The methods were combined in the data collection process until the data saturation point was reached. The saturation point is reached when additional data and analysis adds no new information or understanding. In grounded theory, data collection is an iterative and flexible process and it is driven by the materialising theory (Locke, 2008).

The categories of respondents for the study included Chief Executive Officers, heads of Procurement and Human Resource Managers who were part of top management, and practicing HND Purchasing and Supply graduates. The industries surveyed for the study were, Manufacturing, Education, Distribution, Banking and Hospitality (hotels). These industries were used on the basis of them being perceived to be the key market destinations for the practicing HND Purchasing and Supply graduates. Interviewees were purposefully selected using availability and willingness to participate as key criteria. This sampling technique was used because in a research like this the researchers have to hand pick the subjects or respondents who in the opinion of the researchers have the knowledge and information the researchers are interested in. Locke (2008) argues that sampling in grounded theory always proceeds on theoretical grounds, to find information-rich sources on a particular phenomenon.

A total of 3 focused group discussions made up of 15,21 and 28 participants were conducted in addition to 50 one-on-one face-to-face interviews comprising 20 senior managers from 20 organisations (employers) and 30 practicing HND Purchasing and Supply graduates. The focus group discussions were an intensive and a direct engagement with the research participants that enabled the conceptualisation of categories. Categories are the set of similarly patterned empirical observations. Semi-structured interviews were used as this provided the advantage of exploring issues of interest further when they emerged in the conversations. The semi-structured interviews were further used to explore the categories developed from the focus group discussions.

Documentary analysis was used to complement data collected from the focus group discussions and the semi-structured interviews. Documents analysed included the syllabus and study materials for the HND Purchasing and Supply programme. Upon the completion of interviews, all audio-taped data were transcribed into word format. Thematic analysis (Silverman, 2005) was employed to reveal recurring themes from the data which was termed as categories. The process involved obtaining an overview of the material and identifying patterns and major ideas emerging from the interviews. Findings emerging from the analyses are discussed in the next section.

\section{Results and Discussions}

On the whole, interviewees $(85 \%$ of the HND Purchasing and Supply practitioners) admitted that strategic skills, process management skills, team skills, decision-making skills, behavioral skills, negotiation skills and quantitative skills are important in their daily operations. The emergence of these skills set as being relevant to the operational needs of the practitioner confirms the skills set prescriptions as 
posited by Giunipero et al., (2006) and Giunipero and Pearcy (2000).

The majority of the CEOs however revealed that HND purchasing and Supply practitioners lack managerial skills, confidence (psyche), analytical skills, critical thinking skills, specification development skills, computer skills in terms of data entering, word processing, excel and power point. These skills set constitute components of a sophisticated set of procurement skills and competences needed for managing the buyer-supplier interface (Cousins and Spekman, 2003). The views were equally expressed that although the Public Procurement Authority (PPA) organizes some internship for HND Purchasing and Supply graduates when they were in school, they still lacked hands-on/ practical experience. This is however to be expected given the claim by the practitioners that their internship experience did not expose them to any serious world of practices as majority claimed their internship experience predominantly centered on running errands for offices.

Interviewees cited Public Sector Procurement, Shipping and Forwarding, Logistics Management and Operations Management as key skill source for the purchasing and supply profession which unfortunately are excluded from the HND Purchasing and Supply curricula. Particularly in the public sector employment, HND Purchasing and Supply practitioners were found to be placed as junior staff as prescribed by government policy. Interviewees indicated that the professionalism of the practicing HND purchasing and supply graduate has more room for improvement. Unfortunately, the availability of professional and practical training opportunities on the job seems to be very much limited due to the non-availability of funds for staff development.

Nearly all the practicing HND purchasing and supply graduates shared the view that teaching methods in the Polytechnic's HND Purchasing and Supply programme are more theoretical than practical. This, the interviewees believed is contributed to by the fact that most teaching staff engaged in delivering the purchasing and supply curricula have no industrial experience. One interviewee comments that "the read to teach approach seriously undermines the essence of the HND programme". An interesting revelation was the finding that in both the private and public sectors, other professionals such as Marketing, Engineering etc. were found in top positions of the procurement function, whilst a lot of the HND Purchasing and
Supply practitioners were found in supporting roles. The next sections examine the key data observations and category development emerging from the constant comparison method as the basis for the analysis.

\subsection{Industry's expectations of the skills set of HND Purchasing and Supply graduates}

Majority of the interviewees were of consensus that the HND Purchasing and Supply graduates enter industries with a set of skills set relevant to practice. The contention however, is that employers observe a shortfall in the overall skills requirement for effective practice. The skills deficiency was identified as the inability to write reports and communicate effectively; lack of critical analytical thinking skills; profound weakness in statistical analysis; and inability to work without or with little supervision. With this level of skills deficiency, the ability of these graduates to impact on the financial performance and operational efficiency (Cousins et al., 2006) of the firm would be very much limited.

Practising HND Purchasing and Supply graduates described the key skills relevant to their practice to include strategic management skills, operations and process management skills, team skills, decision-making skills, behavioural skills, negotiation skills and quantitative skills in line with the literature (Tassabehji and Moorhouse, 2008; Giunipero et al., 2006). Though the majority of the practitioners (over 80\%) claim their level on these skills is high, we found this claim to be inconsistent with the curricula of the programme. An analysis of the curricula for the programme reveals that apart from negotiation skills, very negligible attention is paid to the development of the other skills as admitted by the practitioners. Thus the skills imparted fall short of the skills requirement for the trade, hence confirming the widely held perception of the existence of skills mismatch on the Ghanaian labour market.

\subsection{Skills set required of staff in the supply management function}

Participants shared the view that the supply management function plays a critical role in all organizations. POLY 3 posit that "we procure goods worth billions of Cedis for our operations and without the supply function, we will be adding more costs than profit. The supply management function is an integral part of the firm contributing to meeting 
corporate objectives, so it is very important". POLY 7 supported by adding that "strategically, procurement management becomes the engine of the whole organization, because the request are processed and by the close of the day, what the institution needs in terms of teaching and nonteaching needs are procured by the procurement function. So it's very important". Poly 7 added that it also helps businesses to address client needs while enabling them to realize opportunities for cost savings and better potential returns on investment. When asked the skills set needed to mind the function, the skills mentioned by majority of the respondents included; Strategic thinking, critical thinking, written and interpersonal communications, problem solving, teamwork skills, decision making skills, computer literacy, creativity, and inquisitiveness, negotiation skills and quantitative skills, leadership skills, planning and organizational skills, risks taking skills and professional skills, all of which support earlier findings by Giunipero and Pearcy (2000), Giunipero et al., (2006) and Carla (1992).

\subsection{The skills set deficiencies of the HND Purchasing and Supply graduates}

The focus group discussions resulted in a consensus establishing that a gap exist between the skills set imparted and the relevant skills set required for practice. There was consensus among the employers interviewed that the majority of the HND practitioners lack strategic skills, managerial skills, confidence, analytical skills, critical thinking skills, specification development skills, and have very low proficiency in Microsoft Office applications. This evidence appears to be consistent with our analysis of the curricula.

All the HND Purchasing and Supply graduates interviewed also agreed that indeed they lack some skills requirement to undertake their job roles effectively. It was evident following a critical observation and analysis of the programme curriculum that these skills gap emerges from the deficiencies in the curricula they went through in higher education. To establish whether there are training programmes instituted by employers to fill these gaps, most participants responded in the negative. One of the respondents, Poly 11, expressed; "Ok, currently I am not personally aware because I have been here for close to two years and I have never seen or heard about any training programme" Poly 13 added by lamenting that "the institution doesn't have any plan for training and that training comes with a cost".

\subsection{The relevance of the skills set imparted to HND Purchasing and Supply graduates to practice in industry}

Response from majority of employers and HND Purchasing and graduates suggests that the skill set impart through the HND Purchasing and Supply programme is relevant to practice. . It was also observed that majority of HND purchasing and supply graduates were employed into the supply function of most organizations. This was found to be as a result of government policy to recruit HND Purchasing and Supply graduates into the lower ranks of the supply function. . Thus even though it is perceived to deliver relevant skill set, the level of skills imparted significantly fall short of the extent of skills requirement for effective performance.

\section{Conclusion}

Given that supply management is evolving towards a more strategic orientation (Cousins et al., 2006), it is important for firms to employ purchasing professionals having the skills and abilities required to maximize the purchasing function's contribution to overall corporate performance. Procurement professionals now face a changing and dynamic environment requiring a continuous update of their existing skills so that they can make significant contribution to the firm's financial, operational and strategic success (Tassabehji and Moorhouse, 2008; Giunipero and Pearcy, 2000). Higher education is the knowledge base of industry; it has the responsibility for ensuring that purchasing and supply management professionals are adequately equipped with the relevant dynamic skills essential for meeting industry's needs.

The outcomes of this study indicate that although the skills set imparted through the HND Purchasing and Supply programme is relevant to industry, the level of these skills set fall short of some essential skills, thereby creating a skills gap. The research outcomes again confirms the incidence of skills match on the labour market for the HND Purchasing and Supply programme.

The Polytechnics offering the HND Purchasing and Supply programme have a critical role to play in solving the skills gap as established. The Polytechnics may incorporate the identified deficient skills set into the curriculum for the HND Purchasing and Supply programme in order to enhance the training of 
purchasing professionals and thereby increase their professional competences and visibility.

In conclusion, the study has established the skills shortfalls of the HND Purchasing and Supply programme and identified the relevant practising skills which require inclusion in the curricula for the programme. The paper has thus contributed to enhancing understanding for the skills set requirement for practitioners in supply management. The knowledge from the study may be adopted by higher educational institutions in the design and development of supply chain management related programmes.

\section{References}

Carla, L., (1992). Retraining 50 Million Americans: The Electronically Mediated Solution. Ed, The Official Publication of United States Distance Learning Association, 6 (1), 4-9.

Carr, A. S., Smeltzer, L. R. (2000). An empirical study of the relationships among purchasing skills and strategic purchasing, financial performance and supplier responsiveness. Journal of Supply Chain Management, 36 (3), 40-54.

Cousins, P. D., \& Spekman, R. (2003). Strategic supply and the management of inter- and intra-organisational relationships. Journal of Purchasing and Supply Management, 9, 19-29.

Cousins, P. D., Lawson, B., \& Squire, B. (2006). An empirical taxonomy of purchasing functions. International Journal of Operations and Production Management, 26 (7), 775-794.

Diener E. and Crandall R. (1978) 'Ethics in Social and Behavioural Research.'University of Chicago Press, Chicago.

Elias, P. \& Mckniight, A. 2001. Skill measurement in official statistics; recent developments in the $\mathrm{UK}$ and the rest of Europe. Oxford Economic Papers, 3, pp. 508-40.

Galunic, D. and Eisenhardt, K. 2001. Architectural innovation and modular corporate forms. Academy of management journal, 44, 1229-1250.

Giunipero, L., Handfield, R. B. \& Eltantawy, R. 2006. Supply management's evolution: key skill sets for the supply manager of the future. International Journal of Operations \& Production Management, 26, 822-844.

Giunipero, L.C. \& Pearcy, D.H., 2000. World class purchasing skills: an empirical investigation. Journal of Supply Chain Management, 36 (4), 4 13.
Giunipero, L.C., Denslow, D. \& Elantawy, R. 2005. Purchasing and supply chain management flexibility: moving to an entrepreneurial skill set. Industrial Marketing Management, 34 (6), 602-613.

Handfield, R. B., Cousins, P. D., Lawson, B. and Petersen, K. J. 2015. How can supply management really improve performance? A knowledge-based model of alignment capabilities. Journal of Supply Chain Management, 51 (3), 3-17.

Humphreys, P., 2001. Designing a management development programme for procurement executives. The Journal of Management Development, 20 (7), 604-626.

Humphreys, P., Mcivor, R. \& Mcaleer, E. 2000. Reengineering the purchasing function. European Journal of Purchasing \& Supply Management, 6, 85-93.

Kolchin, M. \& Giunipero, L., 1993. Purchasing Education and Training: Requirements and Resources. Center for Advanced Purchasing Studies, Tempe, AZ.

Locke, K. 2008. 'Grounded theory' In: Thorpe, R. and Holt, R. ed. The Sage Dictionary of Qualitative Management Research, Sage, London.

Peterson, O.T. \& Van Fleet, D.D. 2004. The ongoing legacy of R.L.Katz: An updated typology of management skills. Management decision, 42 (10), 1297-1308.

Sauber, M.H., Mcsurely, H.B. \& Tummala, V.M.R. 2008. Developing supply chain management program: a competency model. Quality assurance in Education, 16 (4), 375- 391.

Silverman, D. (2005). Doing qualitative Research $2^{\text {nd }} \mathrm{Ed}$. London. Sage.

Strauss, A.L. \& Corbin, J. 1998. Basics of Qualitative Research: Techniques and Procedures for Developing Grounded Theory, Sage Publications, Berkeley, CA.

Tassabehji, R. \& Moorhouse, A. 2008. 'The Changing Role of Procurement: Developing Professional Effectiveness. Journal of Purchasing and Supply Management, 14 (1), 5568

The Public Procurement Act of Ghana, Act 663 of 2003

Thomas, R. W., Esper, T. L. \& Stank, T. P. 2011. Coping with time pressure in interfirm supply chain relationships. Industrial Marketing Management, 40, 414-423. 
Thurow, L. 1994. New game, new rules, new strategies. RSA Journal CXLII (5454), 5056.
World Economic Forum. 2014. Matching skills and labour market needs: building social partnerships for better skills and better jobs. Available at http://www3.weforum.org/do /GAC/2014/WEF_GAC_Employment_M atchingSkillsLabourMarket_Report_2014.p df (accessed on March 2, 2015) 